\title{
Pedro Piedras Monroy, La siega del olvido: memoria y presencia de la represión. Madrid: Siglo XXI de España, 2012, 302 págs.
}

No puede ser tarea fácil para el historiador hacer la crónica de una parte de la vida (y de la muerte) de su propia familia, lo cual es, de algún modo, historiarse a uno mismo; más aún cuando la historia a la que ha de enfrentarse está (en buena medida) hecha de sangre, marginación y olvido, y presenta heridas que, décadas y generaciones después, siguen sin cerrarse. Si resulta técnicamente imposible que haya ningún relato, de la especie que sea, que pueda ser pura e idealmente objetivo, más imposible aún tiene que ser describir con objetividad la represión que se ensañó con las generaciones inmediatamente anteriores de la propia familia, por la vía primero del crimen, y después de una desmemoria inducida por décadas de represión directa e indirecta.

Pedro Piedras Monroy, historiador reconocidísimo (con obras como Genealogía de la Historia, en colaboración con José Carlos Bermejo Barrera), ${ }^{1}$ especialista en la obra de Max Weber (con libros como Max Weber y la crisis de las ciencias sociales o Max Weber y la India), ${ }^{2}$ traductor al español de algunas de las obras más densas y complejas de la historiografía y de la teoría de la historia universal, ${ }^{3}$ nieto de un abuelo (otro Pedro Piedras) que fue asesinado por los golpistas que provocaron la guerra civil española, y miembro de una familia que vivió y vive la larguísima noche de la injusticia, ni siquiera ha intentado ponerse en el papel de puro cronista de la cadena de injusticias que, desde 1936, llenó de bajas (físicas y simbólicas) su árbol genealógico. La crónica que ha preferido construir, inspirado tanto en las teorías de la memoria del propio Bermejo, de Assman, ${ }^{4}$ Irwin-Zarecka ${ }^{5}$ o Warnock, ${ }^{6}$ muy cerca del concepto de "Postmemoria" de Marianne Hirsch, ${ }^{7}$ pero también deudor de las ideas de narradores como Marcel Proust, Salman Rushdie o W. G. Sebald, ${ }^{8}$ es radicalmente subjetiva, personal, incluso emotiva, hasta entreverada de elegías e improperios en que su voz en primera persona se proyecta sin complejos. Opción intachablemente ética, plenamente legítima, que no entra en contradicción, sino que queda más bien avalada y reforzada por su oficio de experto historiador. Y que han cultivado antes, más fuera que dentro de nuestras fronteras, maestros prestigiosísimos que se han enfrentado a la carga pesadísima del Holocausto nazi, de las purgas estalinistas o maoístas, de las dictaduras de Pinochet o Videla y de tantos otros genocidios desde la doble condición de víctimas (o de descendientes de víctimas) y cronistas. Y por tanto desde el lugar donde se cruzan el compromiso moral con el intelectual, o lo que algunos antropólogos llamarían la

\footnotetext{
${ }^{1}$ J. C. Bermejo Barrera y P. A. Piedras Monroy, Genealogía de la Historia (Madrid: Akal, 1999).

${ }^{2}$ P. Piedras Monroy, Max Weber y la Crisis de las Ciencias Sociales (Madrid: Akal, 2004) y Max Weber y la India (Valladolid: Universidad de Valladolid, 2005).

${ }^{3}$ Entre otras, las de D. Lowenthal, El Pasado es un País Extraño (Madrid: Akal, 1998), la de S. Kalyvas, La Lógica de la Violencia en la Guerra Civil, (Madrid: Akal, 2010) o la de A. N. Viesielovskii, Poética Histórica (Madrid, Akal, en prensa).

4 A. Assmann y U. Frevert, Geschichtsvergessenheit, Geschichtsversessenheit. Vom Umgang mit deutschen Vergangenheiten nach 1945 (Stuttgart: Deutsche-Verlags-Anstalt, 1999).

${ }^{5}$ I. Irwin-Zarecka, Frames of Remembrance. The Dynamics of Collective Memory (New Brunswick, New Jersey: Transaction Publishers, 1994).

${ }^{6}$ M. Warnock, Memory (Londres: Faber and Faber, 1987).

7 Por ejemplo, M. Hirsch, Family Frames. Photography narrative and postmemory (Cambridge, Massachusetts: Harvard University Press, 1997).

${ }^{8}$ En la obra se reconocen las huellas de obras como À la recherche du temps perdu (En busca del tiempo perdido) de Proust, Midnight's Children (Hijos de la Medianoche) de Salman Rushdie o Die Ausgewanderten (Los emigrados) de W. G. Sebald.
} 
visión emic (la de los actantes involucrados en un suceso o relato) y la visión etic (la de los observadores que aspiran a dar cuenta de tales sucesos o relatos).

Capacidades y registros técnicos le hubieran sobrado a Pedro Piedras Monroy si hubiera querido hacer un discurso convencionalmente historiográfico. Pero no era eso, ni mucho menos, lo que él se propuso hacer en este libro: lo que le ha salido ha sido otra historiografía más cercana y más sincera, que no por estar atravesada de emoción y construida desde el yo (o más bien desde el nosotros englobador de la familia) pierde rigor; gana, por contra, solidez, empatía, capacidad de convicción, además de acceso a documentos e informaciones que a un historiador convencional le estarían negadas. Su relato acaba siendo no solo un discurso historiográfico, sino también un mecanismo narrativo delicadísimo que tiene algo de confesión, de catarsis, de homenaje a las víctimas, de ajuste de cuentas con los verdugos, de exploración de los límites no solo de la memoria y del relato, sino también de las emociones y sentimientos.

Su historia parte de un momento y de unas circunstancias muy concretas: "A mi abuelo Pedro lo asesinaron un 2 de enero de 1938 en la plaza de toros de Cáceres; tenía veinticinco años. En aquel día preciso empezó mi carrera como historiador. Su memoria y sus fotos volvieron a mi abuela con unos compañeros de campo de concentración que pasaron por Nava del Rey [Valladolid, pueblo de toda la familia] camino de Toro. Mi abuelo era el único anarquista de su pueblo; su hijo, de once meses a su muerte, fue mi padre, que se apellidó Piedras (y no Hidalgo) porque mi abuela, que no estaba casada, luchó durante años porque le devolvieran el apellido de su padre. Toda mi familia paterna fue asesinada o encarcelada. Los últimos encerrados fueron amnistiados en el 44. Uno de ellos, Ángel Piedras, hermano de mi abuelo, cuando salió de la prisión consagró toda su vida a tres cosas; trabajar, llevar su familia y mantener la memoria viva de los muertos, de los encarcelados y de los oprimidos de su pueblo. Todos los componentes de la generación de mis padres fueron sirvientes o jornaleros y después emigrantes. Mis padres se fueron a Vizcaya, donde nacimos mi hermana Elvira y yo. Mi familia, la emigrada y la no emigrada, siguió el ejemplo de mi tío Ángel y su viaje a la memoria. La mayoría fueron comunistas. Cada verano, al volver a Nava del Rey, acudía yo casi a diario a hablar con mi tío Ángel, sentado a la puerta de su casa. Con el encuentro, volvían las historias, volvían las crónicas que mi tío escribía, volvían las listas con nombre, apellido, mote, lugar de detención, lugar de confinamiento, lugar de ejecución...". 9

Ángel Piedras escribió, muchos años después de los asesinatos de la Guerra Civil, de los meses que pasó condenado a muerte y de su indulto en 1944, una serie de Cuadernos (Cuaderno de los recuerdos, de la dedicatoria, Memorias de un campesino, Recordando lo pasado, Cuaderno de Pedro Piedras) y también algunos Fragmentos, Listas sueltas y Ripios cuya transcripción constituye el corazón de este libro. Su estilo literario es toscamente ingenuo, como cabe esperar de un campesino que no tuvo a su alcance, ni mucho menos, la posibilidad de recibir una formación superior. Pero es también, a cambio de eso, un estilo emotivo, sincero, nervioso, rezumante de humanidad, sin dobleces. Los recuerdos que reflejó en sus diferentes cuadernos se repiten, cruzan o solapan (pero no se contradicen) unas cuantas veces, porque él nunca tuvo in mente escribir un libro formal ni levantar una arquitectura narrativa sofisticada,

\footnotetext{
${ }^{9}$ Véase p. 34.
} 
sino dejar unas memorias personales, legar al futuro un testimonio vivo de unos sucesos que los muertos no podían ya relatar.

Es lástima que Ángel Piedras se viese obligado a confiar lo que recordaba al papel y a la pluma. La cultura suya, la del mundo que él había vivido, era una cultura esencialmente oral, y si su testimonio hubiese sido vertido en una grabación sonora o recogido, por ponernos a soñar, en un documento audiovisual, le mostraría en un territorio que dominaría seguramente más, dueño de unos recursos pragmáticos y capaz de unas intensidades expresivas mucho más directos y articulados que los que puede transmitir el frío papel.

Pero la merma inevitable en los valores discursivos no resta a los cuadernos que nos dejó ningún valor histórico, cultural ni ético. En realidad, tampoco le quita valores puramente expresivos, aunque sí los reformula y los reconduce. El hecho de que, cuando ya anciano, decidiera Ángel Piedras sincerarse, pero en la penumbra de su casa, confiado a la privacidad de unos cuadernos, tiene un significado enorme: sus listas de las 94 personas asesinadas durante la guerra de 1936-1939 en el pequeño pueblo de Nava del Rey (114 más sufrirían prisión en la posguerra), dibujadas con vacilante letra campesina, levantan un discurso completamente diferente del de las listas de caídos por Dios y por España que los vencedores recitaron y recitan siempre en voz alta, pública y orgullosa, grabado en los lugares más visibles de iglesias, edificios y plazas de todo el país, y proclamado en ceremonias de canonización solemnísimas que se celebran en Roma en presencia siempre de altas autoridades del estado español a las que no se ve cuando se abre ninguna fosa común con restos de los vencidos asesinados.

El que estemos ahora reflexionando sobre las listas y cuadernos de Ángel Piedras, el que este libro haya sido finalmente publicado, el que sea objeto de atención por parte de los historiadores y se halle en muchísimas bibliotecas, el que su testimonio se haya podido incorporar, aunque tarde, al corpus de textos más significativos y esenciales con que contamos para entender lo que fue la Guerra Civil y la represión subsiguiente, todo eso demuestra que algún cálculo no les salió del todo bien a quienes se tomaron el trabajo de asignar las voces silenciosas a quienes perdieron y las voces cantantes a quienes ganaron la Guerra Civil; igual que demuestra que desde una mesa, una silla y unos cuadernos de pueblo, alejados de los centros de decisión política y de las latiniparlas académicas, se puede modificar en alguna medida si no la realidad, sí la historia, o al menos la manera de expresarla, percibirla e interpretarla.

Pero este libro fundamental acerca del lenguaje de la derrota y de la victoria durante la guerra y la represión es también una refutación, y de las más fundamentadas, vigorosas y hasta ingeniosas que se han hecho nunca, de todo el relato de la Transición, que buena parte de la clase política española ha buscado elevar a la categoría de utopía social perfecta e imponer como dogma de aceptación obligatoria para todos los españoles desde la escuela. Admira, por ejemplo, el intensísimo capítulo XXII, "Cuentos de hadas", con su fabulosa deconstrucción del cuento del padrastro malo (Franco), el príncipe-rey bueno (Juan Carlos I) y la épica restauración de la felicidad perdida del reino, gracias al concurso de todo un esforzado plantel de paladinespolíticos que, si hace siglos hubieran tenido que montar sobre corceles briosos, condujeron a su grey de la Transición montados sobre sus coches oficiales. ${ }^{10}$ Asombra,

${ }^{10}$ Véase p. 235. 
también, la amarga equiparación de los vencidos por la guerra, el olvido, el desprecio, el silencio, la edad, con la figura del viejo abuelo Cebolleta, antihéroe de los tebeos del franquismo y de la Transición, encerrado siempre en el recuerdo de unas batallitas que hasta sus más cercanos rehuían y ridiculizaban como relato pasado de moda, senil, despreciable. Metáfora perturbadora, la del abuelo culpable de no poder olvidar, y sobre todo de atreverse a verbalizar sus memorias de guerra, que fue astutamente utilizada, durante muchos años, para desacreditar los recuerdos de quienes envejecían, en muchos hogares españoles, bajo el peso de los crímenes que habían visto y sentido tan de cerca. ${ }^{11}$

Hoy, Ángel Piedras está muerto, como muertos estaban, antes de él, todos los que quedaron apuntados en su lista de asesinados. Pero en Nava del Rey se halla erigido un sencillo monolito con el que sus familiares han recordado (gracias a él y a su lista) los nombres de los asesinados durante aquella infausta guerra. Y el pasado día 15 de julio de 2013 se celebró, en el mismo pueblo, un acto de reivindicación de la memoria en que los descendientes hablaron, en voz alta y pública, sin esconderse ni sentir vergüenza, de sus muertos. No son actos de venganza, aunque tampoco son actos de una justicia que resulta ya imposible. Son actos de simple pero necesaria reparación.

El libro de Pedro Piedras Monroy se cierra con un "Postludio" ("España: la imposible memoria cívica") de José Carlos Bermejo Barrera. ${ }^{12}$ Fundamentadísimo en la construcción historiográfica en el que compara la diferente forma en la que países como España y Alemania han afrontado el horror de su memoria; revisa el concepto de memoria cívica desde sus orígenes griegos y redunda en los errores principales que han venido arrastrándose en España en este ámbito desde la época de la represión hasta la actualidad; un ensayo riguroso pero también emotivo, doloroso, devastador en el detalle de casos, miserias e injusticias.

José Manuel Pedrosa

Universidad de Alcalá

jmpedrosa2000@yahoo.es

Fecha de recepción: 23 de octubre de 2013.

Fecha de aceptación: 24 de diciembre de 2013.

Publicado: 30 de junio de 2014.

Para citar: José Manuel Pedrosa, "Pedro Piedras Monroy, La siega del olvido: memoria y presencia de la represión. Madrid: Siglo XXI de España, 2012, 302 págs.", Historiografias, 7 (enero-junio, 2014): pp. 146-149

http://www.unizar.es/historiografias/historiografias/numeros/7/res_pedrosa.pdf

\footnotetext{
${ }^{11}$ Véanse pp. 238-239.

${ }^{12}$ Véanse pp. 291-302.
} 